\title{
Nuclear transcription factors in mammalian mitochondria
}

\author{
Sarah Leigh-Brown ${ }^{1,2}$, José Antonio Enriquez ${ }^{3,4}$ and Duncan T Odom²*
}

\section{Abstract \\ Nuclear transcription factors have been detected in mammalian mitochondria and may directly regulate mitochondrial gene expression. Emerging genomics techniques may overcome outstanding challenges in this field.}

Mammalian cells store genetic information in two cellular compartments: the nucleus and the mitochondria. Mitochondrial DNA is packaged, handled and inherited independently of the nuclear genome, and far less is known about the regulation of mitochondrial gene expression compared with that of nuclear genes. As the singular site of the generation of adenosine triphosphate (ATP) by oxidative phosphorylation in the eukaryotic cell, the regulation of mitochondrial functions are complex and must be tightly regulated to respond to cellular metabolic requirements [1,2]. The majority of proteins present in mitochondria are encoded and transcribed in the nucleus [3], but the mitochondrial genome encodes a handful of proteins crucial for the generation of ATP (Figure 1). These proteins are transcribed and translated in the mitochondrial matrix and do not enter the cytoplasm $[4,5]$. Because both the nuclear and the mitochondrial genomes contribute to the mitochondrial proteome, their regulatory coordination is critical to cell survival and energy homeostasis [6]. This coordination is complicated by the distinct packaging and environment of the two genomes (Box 1).

Regulation of mitochondrial gene expression is poorly characterized relative to that of the nucleus. Nuclearencoded transcriptional regulatory proteins called transcription factors can potentially influence mitochondrial gene expression in two quite different ways - indirectly or

\footnotetext{
*Correspondence: duncan.odom@cancer.org.uk

'Cancer Research UK, Cambridge Research Institute, Li Ka Shing Centre,

Robinson Way, Cambridge, CB2 ORE, UK

Full list of author information is available at the end of the article
}

directly. They can act as 'indirect regulators' by regulating the transcription of nuclear-encoded genes relevant to mitochondrial function and biogenesis. Indirect regulators include the nuclear respiratory factors 1 and 2 (NRF-1, NRF-2), which regulate the expression of nuclearencoded components of the mitochondrial respiratory chain and the basal transcription machinery [7] (Figure 2). Alternatively, they can be imported into the mitochondrion and alter transcription from the mitochondrial genome as 'direct regulators' of mitochondrial gene expression (Figure 2). Whereas the majority of mitochondrial transcriptional regulators act indirectly, a handful of nuclear transcription factors appear to act in both environments and have been partly characterized as direct regulators of mitochondrial gene expression.

Nuclear transcription factors were first identified as acting in mitochondria 15 years ago, and these early reports included the glucocorticoid receptor [8], the tumor suppressor p53 [9] and the mitochondrial receptor for the thyroid hormone tri-iodothyronine $\left(\mathrm{T}_{3}\right)$, named p43 [10]. The crucial demonstration that mitochondrial gene expression can be regulated without a change in nuclear gene expression came a few years later, using biochemically isolated mitochondria. The observation that thyroid hormone treatment of isolated mitochondria altered mitochondrial gene expression despite the absence of a nucleus indicated that mitochondrial gene expression was not only regulated indirectly, via the nucleus. It also suggested that a $T_{3}$ receptor might be acting directly within the mitochondria as a regulator of transcription from the mitochondrial genome.

Mitochondrial dysfunction is known to contribute to aging [11] and to diseases, including cancer [12], diabetes [13] and obesity [14], but despite the boom in transcription factor biology facilitated by emerging technologies such as chromatin immunoprecipitation (ChIP), the mitochondrial role of nuclear transcription factors is understudied. This is in part due to technical challenges of disambiguating indirect regulation from direct regulation when both are mediated by the same transcription factor or signaling pathway. In this review we discuss the methods used to dissect the functions of nuclear and mitochondrial transcription factors, and discuss five 


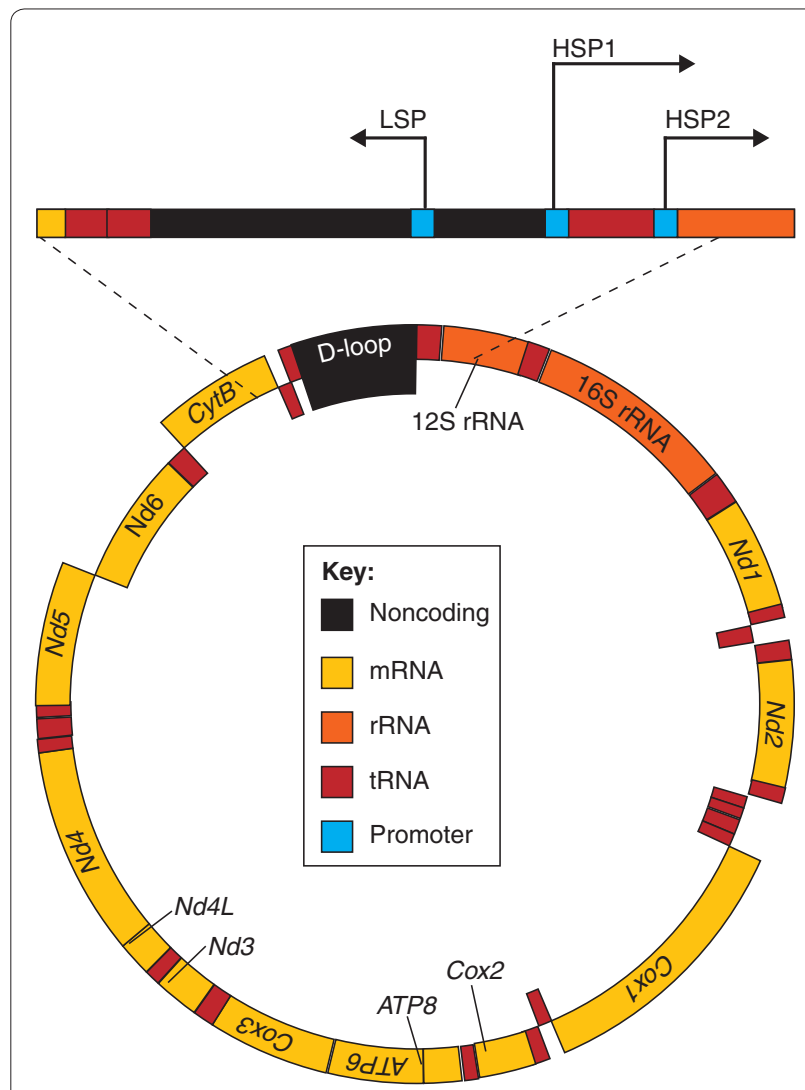

Figure 1. Organization of the mammalian mitochondrial genome. Thirteen protein-coding genes (yellow), twenty-two tRNA genes (red) and two rRNA genes (orange) are encoded on a single circular nucleic acid and transcribed from three promoters (blue): LSP, HSP1 and HSP2, which are situated in a single region called the D-loop, which contains regulatory sequences that control transcription from all three promoters, including motifs for DNAbinding proteins such as Tfam. The inner circle of genes is encoded on the (-) strand and transcribed from the LSP promoter. The outer circle of genes is encoded on the $(+)$ strand and transcribed from the HSP1 and HSP2 promoters. Transcription from HSP2 is terminated distal to the $16 \mathrm{~S}$ rRNA gene. The resulting three polycistronic transcripts are processed by enzymatic excision of the tRNAs (red). ATP6, ATP8, subunits of ATP synthase F0; Cox1, Cox2, Cox3, subunits of cytochrome oxidase; CytB, cytochrome B, Nd1, Nd2, Nd3, Nd4, Nd4L, $\mathrm{Nd} 5, \mathrm{Nd6}$, subunits of NADH dehydrogenase.

well-characterized examples of nuclear-encoded gene regulatory proteins that act in mitochondria.

\section{Techniques for distinguishing nuclear and mitochondrial roles of mammalian transcription factors}

The techniques summarized in Table 1 have been applied to the study of nuclear transcription factors in mitochondria with the aim of addressing three major questions. Is the factor localized to mitochondria? Is the putative mitochondrial role independent from the nuclear role? Does the factor bind to the mitochondrial DNA and/or

\section{Box 1 Mitochondria and mitochondrial gene regulation}

The mitochondrion is the single cellular site of ATP generation via aerobic respiration, and metabolites such as dietary lipids and pyruvate, the metabolic product of glycolysis, are actively transported into mitochondria [79]. As the tricarboxylic acid cycle progresses within the mitochondrial matrix, a series of electrontransfer reactions, known collectively as the electron-transport chain, proceeds between large multiprotein complexes and small electron carriers within the inner membrane and matrix [5]. The resulting electrochemical gradient generates bioavailable ATP via a rotating inner-membrane ATPase, which couples proton flow down a proton gradient to the catalysis of the phosphorylation of ADP to ATP using inorganic phosphate [80].

The mitochondrion is derived from a symbiotic a-proteobacterium [81], and so the mitochondrial genome is packaged and structured differently from the nuclear genome [82]. The sequence of the mitochondrial genome and the translation machinery are also more similar to that of a bacterium than to eukaryotic systems [83], and the mitochondrial transcription machinery is reminiscent of that used by bacteriophages [84]. In contrast to the chromatin-based packaging of the nuclear genome, the mitochondrial genome is packaged into non-chromatin nucleoids involving proteins specific to mitochondria, such as Tfam $[4,85]$. Although the mammalian mitochondrial DNA is small, at around $16.5 \mathrm{~kb}$, it nevertheless encodes 13 protein-coding genes, 22 tRNA genes and 2 rRNA genes, as shown in Figure 1 [86]. Unlike nuclear genes, each of which often has multiple dedicated promoters, all mitochondrial genes are expressed together from only three promoters encoded in the regulatory D-loop region [87], which are recognized by the mitochondrial basal transcriptional machinery: the mitochondrial RNA polymerase (Polrmt), and the mitochondrial transcription factors Tfam and Tfb $2 \mathrm{~m}[4,88]$. The resulting three polycistronic transcripts do not undergo splicing, and are processed by an RNase that excises tRNAs to release the mRNA and rRNA $[9,89]$ before mRNA translation in the mitochondrial matrix.

regulate mitochondrial gene expression? Up to now there has been an emphasis on electro-mobility shift assays (EMSAs) and nuclear reporter constructs to validate the binding of a transcription factor to specific mitochondrial DNA sequences. But given the distinctly different molecular environments involved, claims that nuclear transcription factors directly bind the mitochondrial genome in vivo have been controversial. A more physiological system is to use isolated mitochondria in in organello transcription assays [15]. With the increased availability of genomics techniques and ChIP-grade antibodies, the direct in vivo identification of proteinDNA contacts in mitochondria could become routine [16]. In nuclear transcription studies, ChIP is a gold standard for detecting in vivo interactions between a factor of interest and the genome, and these methods can be readily adapted to mitochondrial investigations. ChIP 


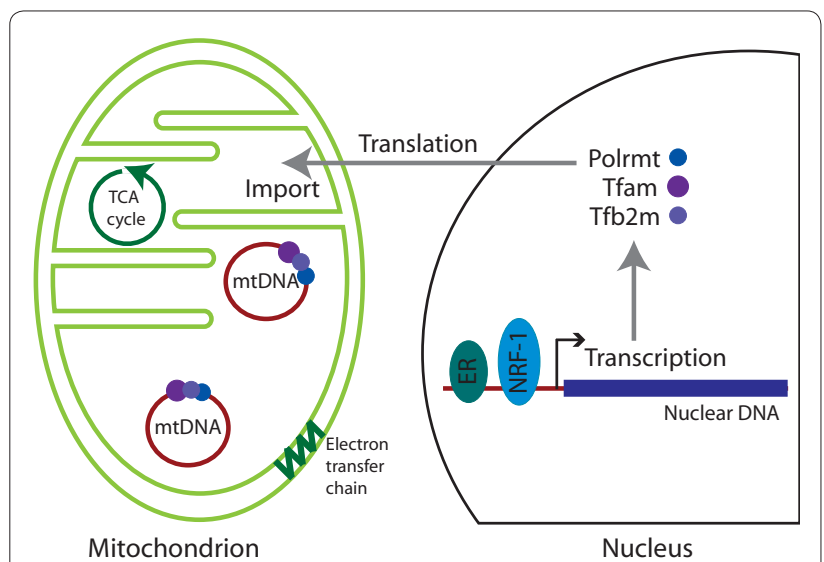

Figure 2. The mammalian mitochondrion. The mitochondrion is the site of ATP generation via the tricarboxylic acid (TCA) cycle and the electron-transport chain, and the mitochondrial genome (mtDNA) exists in multiple copies per mitochondrion. The majority of mitochondrially localized proteins, including the basal transcription machinery (Tfam, Tfb2m and Polmrt), are encoded in the nucleus, where their expression is controlled by nuclear transcription factors (such as the estrogen receptor (ER) and NRF-1). Their mRNAs are then translated in the cytoplasm and the proteins imported into mitochondria.

assays are increasingly performed on native transcriptional regulators rather than on tagged overexpressed protein constructs, and can thus indicate the presence or absence of mitochondrial binding in vivo. The successful use of techniques such as ChIP, immunoelectron microscopy, EMSA, co-immunoprecipitation, and subcellular fractionation followed by immunoblotting is highly dependent on antibody specificity. Indeed, one antibody used to detect the phosphorylated form of the cyclicAMP response element binding protein (CREB) in immunostaining and cellular localization studies was recently shown to cross-react with pyruvate dehydrogenase, an abundant enzyme in mitochondria [17]. This case highlights the need for antibody validation.

Proteomics studies over the past decade have attempted to characterize the complete mammalian mitochondrial proteome $[1,2,18]$. While these studies have revealed the responsiveness of mitochondria to cell signaling and the tissue specificity of mitochondrial function, they have rarely identified direct mitochondrial transcriptional regulators. DNA-damage repair proteins and other DNAbinding proteins seem difficult to detect using mass spectrometry because of their low relative abundance [1]. Subtractive proteomics - the differential detection of proteins in a mitochondrial sample relative to a cytoplasmic/nuclear sample - can increase the sensitivity of a mass spectrometric analysis, but at the cost of not detecting proteins with a role in multiple organelles [2]. Both the proteomics and genomics tools used in mitochondrial studies are improving rapidly, and as a result the number of nuclear transcription factors shown to play a direct role in mitochondrial regulation is likely to increase.

\section{Nuclear transcription factors as direct regulators of mitochondrial gene expression}

The nuclear transcription factors best characterized as direct regulators of mitochondrial gene expression in mammals are the $\mathrm{T}_{3}$ receptor $\mathrm{p} 43, \mathrm{CREB}$, the tumor suppressor p53, signal transducer and activator of transcription 3 (Stat3) and the estrogen receptor. p43 and CREB are transcription factors that can bind mitochondrial DNA to regulate gene expression. p53, Stat3, and, potentially, the estrogen receptor are thought to act as co-regulators, affecting mitochondrial gene expression through protein-protein interactions.

\section{The $\mathrm{T}_{3}$ receptor}

The thyroid hormone $\mathrm{T}_{3}$ is a primary regulator of mammalian mitochondrial biogenesis [19] and can influence mitochondrial function both indirectly and directly. In its indirect role, it binds to members of the nuclear receptor superfamily of transcription factors known as $\mathrm{T}_{3}$ receptor $\alpha$ and $\beta$ ( $T_{3} R \alpha$ and $\left.T_{3} R \beta\right)$ to regulate nuclear gene transcription [20] (Figure 3). Nuclear transcriptional targets of these receptors include genes that stimulate mitochondrial biogenesis, such as those encoding the transcription factor nuclear respiratory factor 1 (NRF-1) and the cofactor PGC-1 $\alpha[21,22]$ as well as the mitochondrial basal transcription factor Tfam [23,24].

$\mathrm{T}_{3}$ also regulates mitochondrial function directly via two pathways: the regulation of nucleotide transport across the inner membrane via a $\mathrm{T}_{3}$-binding adenine nucleotide transporter (AdNT) [25,26]; and control of mitochondrial transcription via the mitochondrially localized $\mathrm{T}_{3} \mathrm{R} \alpha 1$ isoform known as p43 (Figure 3; reviewed in [27,28], see also [10]). Most proteins are imported into mitochondria in an ATP-dependent manner via the protein translocator channel TOM, which recognizes an amino-terminal mitochondrial localization signal that is then cleaved during import. p43, however, is imported into rat liver mitochondria via a different pathway, previously shown for the yeast mitochondrial transcription factor MTF1 [15], which is independent of both TOM and mitochondrial ATP levels, and does not result in cleavage of the imported protein.

One potential mechanism by which transcription factors could be accurately sorted among different cellular compartments is revealed when considering the $\mathrm{T}_{3}$ receptors. It was noticed that a protein construct mimicking a $T_{3} R \beta$ isoform with a truncated amino terminus (which is the form present in most nonmammalian vertebrates) is specifically imported into isolated rat mitochondria, suggesting a role for the 
Table 1. Techniques used to investigate nuclear transcription factors in mitochondria

\begin{tabular}{|c|c|c|}
\hline Method & Summary & References \\
\hline \multicolumn{3}{|c|}{ Experimental question: Is the factor localized to mitochondria? } \\
\hline Subcellular fractionation & $\begin{array}{l}\text { Centrifugation separates the mitochondrial, nuclear and cytoplasmic fractions of a } \\
\text { cell sample. Immunoblotting for known mitochondrial, nuclear and cytoplasmic proteins } \\
\text { assesses the efficiency of the fractionation process. Further immunoblotting establishes } \\
\text { presence of factor of interest in mitochondrial fraction. }\end{array}$ & CREB [38], ER $[4,18,90]$ \\
\hline Immunoelectron microscopy & $\begin{array}{l}\text { Labeling of intact cell preparations with specific antibodies conjugated to a heavy } \\
\text { metal, such as gold. Transmission electron microscopy is used to visually analyze } \\
\text { co-localization of the gold with the distinctly identifiable mitochondria. }\end{array}$ & CREB [38] \\
\hline Mitochondrial import analysis & $\begin{array}{l}\text { Observing the uptake of an in vitro translated radiolabeled protein of interest into } \\
\text { isolated intact mitochondria, in the absence of a nucleus or any external stimulation. }\end{array}$ & CREB [39], p43 [15] \\
\hline Co-immunoprecipitation & $\begin{array}{l}\text { Inference of mitochondrial localization for a protein by characterization of a physical } \\
\text { interaction with a known mitochondrial protein. }\end{array}$ & p53 [56] \\
\hline \multicolumn{3}{|c|}{ Experimental question: Is the putative mitochondrial role independent from the factor's nuclear role? } \\
\hline In organello systems & $\begin{array}{l}\text { Isolation of intact mitochondria and observation of their response to stimulation of the } \\
\text { factor of interest (for example, by addition of a hormone ligand). }\end{array}$ & p43 [30] \\
\hline $\begin{array}{l}\text { Mitochondrion-specific } \\
\text { overexpression }\end{array}$ & $\begin{array}{l}\text { Overexpression of a mitochondrion-specific isoform of a transcription factor or fusion of } \\
\text { a transcription factor with a constitutive mitochondrial localization signal. Altered } \\
\text { transcription from the mitochondrial genome in the absence of altered nuclear target } \\
\text { expression suggests direct regulation of mitochondrial gene expression by that factor. }\end{array}$ & CREB [40], p43 [91] \\
\hline \multicolumn{3}{|c|}{ Experimental question: Does the factor bind to the mitochondrial DNA and/or regulate mitochondrial gene expression? } \\
\hline $\begin{array}{l}\text { Chromatin } \\
\text { immunoprecipitation (ChIP) }\end{array}$ & $\begin{array}{l}\text { Assay of specific protein-DNA interactions by the crosslinking of proteins to DNA } \\
\text { followed by antibody-based enrichment of a protein of interest. The DNA bound to that } \\
\text { factor can then be assayed site-specifically by quantitative PCR, or on a genome-wide } \\
\text { scale by microarray analysis or high-throughput sequencing. Used to detect direct } \\
\text { binding of a factor to mtDNA. }\end{array}$ & CREB [40], p53 [54] \\
\hline DNA footprinting & $\begin{array}{l}\text { Assay of protein-DNA interactions nonspecifically by crosslinking protein to DNA } \\
\text { followed by DNase digestion or dimethylsulfate treatment. Protein-bound DNA } \\
\text { sequences are protected from digestion or methylation. Regions of mtDNA are then } \\
\text { assayed for a change in protection pattern following stimulation of a specific protein } \\
\text { or pathway. }\end{array}$ & p43 [30,32], CREB [40] \\
\hline $\begin{array}{l}\text { Electro-mobility shift assay } \\
\text { (EMSA) }\end{array}$ & $\begin{array}{l}\text { Detects the capacity of a pool of proteins (for example, a mitochondrial extract) to bind } \\
\text { to a short sequence of synthesized DNA, causing it to run slower (and thus 'shift' } h i g h e r \text { ) } \\
\text { than non-complexed DNA on a non-denaturing polyacrylamide gel. The addition of } \\
\text { antibodies against the protein of interest gives specificity. Antibodies can be applied } \\
\text { before mixing extract with DNA, resulting in loss of 'shift', or afterwards resulting in } \\
\text { increased'shift'. }\end{array}$ & p43 [15], CREB [38], ERß [67] \\
\hline Transcriptional reporter assays & $\begin{array}{l}\text { Use of nuclear transcription constructs containing a putative regulatory sequence } \\
\text { derived from mtDNA, upstream of a nuclear promoter and a reporter gene such as } \\
\text { luciferase. Changed expression of the construct following stimulation of the transcription } \\
\text { factor of interest shows that these mitochondrial sequences can act as regulatory } \\
\text { elements when placed in a nuclear context. }\end{array}$ & p43 [15], p53 [56] \\
\hline
\end{tabular}

mtDNA, mitochondrial DNA.

amino-terminal truncation in mitochondrial import [15]. p43 is itself a truncated form of the full-length nuclear transcription factor $\mathrm{T}_{3} \mathrm{R} \alpha$ and is translated from an alternative start site in the $\mathrm{T}_{3} \mathrm{R} \alpha$ mRNA [15,29]. The expression of $\mathrm{p} 43$ is, however, regulated independently from the full-length $\mathrm{T}_{3} \mathrm{R} \alpha$ and it shows a distinct tissuespecific pattern of expression [29].

$\mathrm{T}_{3}$ receptors associate with nuclear DNA in a sequencespecific manner via $\mathrm{T}_{3}$-response elements (T3REs), DNA motifs first recognized in the promoters of $\mathrm{T}_{3}$-responsive genes. Multiple T3REs have been identified in the mouse mitochondrial genome that confer responsiveness to thyroid hormone in nuclear reporter assays, and p43 binds to these sequences in vitro in EMSAs. These techniques do not, however, address the question of whether p43 binds mitochondrial DNA in vivo under physiological conditions. This was partly addressed in a series of studies utilizing induced-hypothyroid rats, in which physiological $\mathrm{T}_{3}$ levels were found to regulate mitochondrial gene expression directly in vivo. Mitochondria isolated from the livers of these rats showed that changes in physiological thyroid hormone levels altered the relative levels of mitochondrial mRNA and rRNA, which correlated with altered protein occupation of the mitochondrial D-loop as determined by DNA footprinting [30]. The independence of this direct 


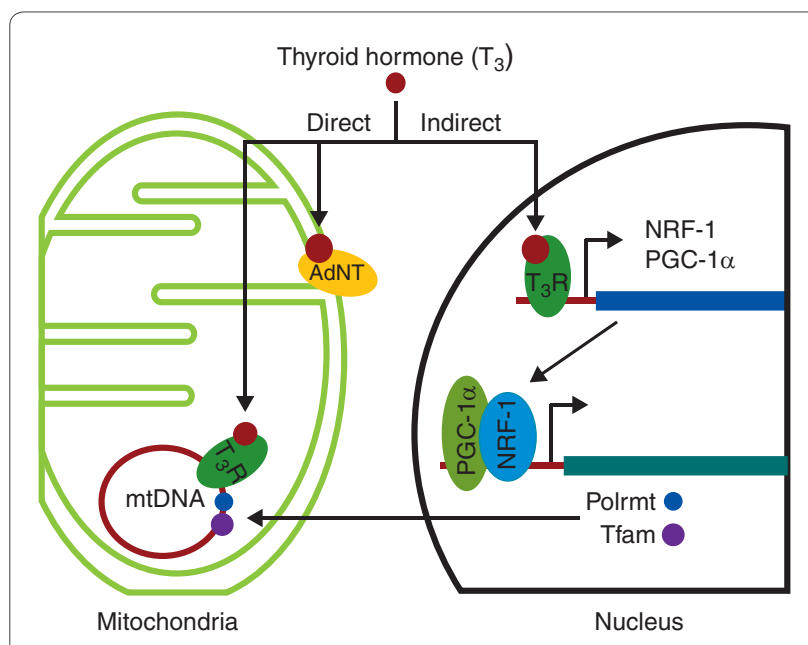

Figure 3. Regulation of mitochondrial function by a thyroid hormone. Indirect regulation: binding the thyroid hormone triiodothyronine $\left(T_{3}\right)$ to the $T_{3}$ receptor $\left(T_{3} R\right)$ leads to upregulation of transcriptional regulators of mitochondrial biogenesis, such as NRF-1 and PGC-1a. NRF-1 and PGC-1 a then can upregulate transcription of the nuclear-encoded mitochondrial basal transcription machinery (Tfam, Polrmt), which stimulates mitochondrial DNA (mtDNA) replication and mitochondrial biogenesis. Direct regulation: thyroid hormone binds directly to two mitochondrial proteins, the inner mitochondrial membrane adenine nucleotide transporter (AdNT) and a truncated version of $\mathrm{T}_{3} \mathrm{R}$ located in the mitochondrial matrix. $\mathrm{T}$ regulates expression from the mitochondrial genome via $T_{3} R$, which may bind directly to the mitochondrial DNA.

mitochondrial role for $\mathrm{T}_{3}$ from the well-characterized indirect role was shown when isolated mitochondria from hypothyroid rats were treated with $\mathrm{T}_{3}$ and the mitochondrial mRNA:rRNA ratio and the pattern of DNA footprinting returned to that of normal rats [30]. This indicated that $T_{3}$ regulates mitochondria directly and suggested that this pathway may involve a mitochondrial $\mathrm{T}_{3}$ receptor with similar binding preferences to the nuclear form.

The role of $\mathrm{p} 43$ in $\mathrm{T}_{3}$-mediated regulation of mitochondrial transcription was confirmed using the same in organello system from induced-hypothyroid rats to show that the addition of $\mathrm{p} 43$ (translated in vitro to avoid possible contamination by cellular components) stimulated mitochondrial gene transcription in the presence of $\mathrm{T}_{3}$ [15], whereas $\mathrm{T}_{3}$ treatment in the absence of $\mathrm{p} 43$ did not stimulate mitochondrial gene expression [15]. In validation of the mitochondrial role of $\mathrm{p} 43$ in vivo, mice overexpressing p 43 under the control of a muscle-specific promoter exhibited increased mitochondrial gene expression and mitochondrial biogenesis in muscle, and had increased oxidative metabolism, with body temperature $0.8^{\circ} \mathrm{C}$ higher than control mice [31].

The direct regulation of mitochondrial transcription by $\mathrm{T}_{3}$ is complex and highly tissue specific. In organello studies that demonstrate the responsiveness of liver mitochondrial transcription to $\mathrm{T}_{3}$ also demonstrate that mitochondria from the heart are not regulated in this manner. Rather, $T_{3}$ regulation of mitochondria from the hearts of the induced-hypothyroid rats is indirect - via the nucleus - and primarily at the level of regulating mitochondrial DNA copy number [32]. This complexity is likely to be shared by other transcription factors with a direct mitochondrial activity, and it may explain why early work did not detect direct binding of a protein to the proposed mitochondrial T3REs [30] despite the requirement of a DNA-binding domain in $\mathrm{p} 43$ for the observed mitochondrial function [15]. Regardless of this outstanding debate over the location of p43 binding to mitochondrial DNA, evidence is overwhelming that p43 is localized to the mitochondria in rat liver, where it binds to the mitochondrial genome and regulates mitochondrial transcription. A great deal remains to be studied regarding p43 in mitochondria - for example, it is not clear whether this regulatory pathway is conserved within mammals, or in which other tissues it is utilized. Nevertheless, the studies on thyroid hormone and thyroid hormone receptor were the first direct illustration that mitochondrial gene expression is regulated independently from nuclear gene expression and introduced a key model system for the study of nuclear transcription factors in mitochondria.

\section{Cyclic-AMP response element binding protein (CREB)}

The transcription factor CREB regulates nuclear gene expression in response to a diverse range of stimuli $[33,34]$. CREB is activated by phosphorylation, either by the cyclic-AMP responsive protein kinase A (PKA) or by other kinases, including mitogen-activated protein kinases (MAPKs) and $\mathrm{Ca}^{2+} /$ calmodulin-dependent kinases (CaMKs) [35]. A self-contained CREB pathway exists in mitochondria, which involves PKA [36], cyclic AMP [37] and CREB [38]. On stimulation, this pathway induces binding of phosphorylated CREB to cyclic-AMP response elements (CREs) in the mitochondrial DNA D-loop and regulation of mitochondrial gene expression $[39,40]$ (Figure 1).

CREB was first localized to rat brain mitochondria by subcellular fractionation followed by immunoelectron microscopy [38]. Despite not having a classical mitochondrial localization signal, the transport of labeled CREB into isolated rat liver mitochondria depends on the mitochondrial translocator TOM, the import route for most proteins into mitochondria [39]. The mitochondrial pool of CREB can co-immunoprecipitate with the chaperone protein mtHSP70 [40], suggesting a mechanism of targeting to the mitochondria that is dependent on chaperone proteins rather than on a mitochondrial localization signal, as has been shown for p53 [41]. Once 
in mitochondria, CREB is regulated by phosphorylation in response to the same stimuli as in the nucleus, and in vitro can bind oligonucleotides bearing the consensus CRE sequence [38]. Binding of CREB to the mitochondrial D-loop (Figure 1) has been detected in vivo using ChIP [36] and DNase footprinting, and is dependent on mitochondrial PKA activity $[40,41]$. Unlike p43, mitochondrial localization of CREB has been identified in multiple mammalian species and tissues $[36,38,39]$.

An overexpression construct that selectively increases levels of CREB in mitochondria was used to distinguish CREB nuclear and mitochondrial regulatory roles in primary cultured neurons from rat brain [40]. These increases in mitochondrial CREB perturbed mitochondrial gene expression without altering the expression levels of CREB's nuclear target, c-fos [40]. The mRNAs of mitochondrially encoded NADH dehydrogenase subunits 2,4 and 5 (Figure 1) were specifically upregulated; conversely, these mRNAs were downregulated on treatment with a dominant-negative form of CREB in the mitochondria [40].

\section{Tumor suppressor protein p53}

The tumor suppressor protein p53 is a well-known example of a nuclear transcription factor with a role in mitochondria [42]. First identified by its transcriptional regulatory function [43], p53 also has non-transcriptional functions, and has been implicated in apoptosis [44], senescence [45], autophagy [46], DNA-damage repair and cell-cycle arrest [47].

In mitochondria, p53 directly regulates apoptosis via protein-protein interactions at the outer membrane, and this function has been reviewed thoroughly elsewhere $[48,49]$. However, there is considerable evidence for a second mitochondrial role for $\mathrm{p} 53$, in mitochondrial DNA maintenance and in mitochondrial DNA-damage repair. Co-immunoprecipitation of p53 with the mitochondrion-specific transcription and mitochondrial DNA packaging factor Tfam suggests that p53 may regulate DNA-damage repair in mitochondria [50], as it does in the nucleus [51,52]. In KB human epidermoid cancer cells and in HCT116 adenocarcinoma cells, p53 physically interacts with Tfam, with the effect of enhancing the binding of Tfam to cisplatin-damaged DNA at the expense of oxidized DNA, in a reversal of Tfam's normal binding pattern [50].

p53 also seems to play a role in mitochondrial baseexcision repair. In a nucleus-free in vitro system derived from the mitochondria of mouse liver, p53 can stimulate the gap-filling function of the mitochondrial DNA polymerase mtPOL $\gamma$ [53]. A physical interaction between p53 and mtPOLy in vivo has been detected in HCT116 cells [54], where p53 enhances the replication function of mtPOLy and interacts with the mitochondrial genome.
The observed binding of p53 to the mitochondrial genome was stimulated by, but not dependent on, DNA damage, suggesting that the role of p53 at the mitochondrial DNA may not be confined to the DNA-damage response. Furthermore, in studies comparing mitochondria from p53-deficient cell lines with those from isogenic p53-positive lines, p53 appears to provide an endogenous proofreading function for $\mathrm{mtPOL} \gamma$ during mitochondrial DNA replication [55].

Despite clear localization of p53 to the mitochondrial matrix and a number of direct associations with mitochondrial DNA, evidence that p53 can bind sequence-specifically to regulate expression of mitochondrially encoded genes remains elusive. Sequences from the mouse mitochondrial genome that resemble the nuclear binding motif of p53 confer p53 responsiveness in nuclear reporter assays [56], but there is no evidence that $\mathrm{p} 53$ regulates transcription from the mitochondrial genome. Regardless of whether p53 directly regulates mitochondrial transcription, it plays important mitochondrial roles in apoptosis, DNA integrity and response to stress.

\section{Signal transducer and activator of transcription 3 (Stat3)}

Stat3 was first detected in mitochondria as a result of its functional association with GRIM-19, a subunit of the respiratory electron-transport chain NADH dehydrogenase (Complex I), which functions in the transfer of electrons from NADH to the respiratory chain $[57,58]$. In the nucleus, Stat 3 mediates the transcriptional response to growth factors such as interleukin-6 and epithelial growth factor [59]. Differences between Stat3 function in the mitochondria and nucleus are exemplified by the fact that the mitochondrial pool of Stat3 mediates oncogenic transformation by the small GTPase H-Ras, a process that is mechanistically distinct from how nuclear Stat3 supports oncogenic transformation by the viral oncogene v-Src [60]. Both Stat3-knockdown cell lines and Stat3knockout mice show disrupted electron-transport chain function [61], which suggests that Stat3 directly regulates mitochondrial function via its effects on the electrontransport chain. Engineered Stat3 mutant proteins have shown that the nuclear role and the mitochondrial role can be functionally isolated [61].

\section{The estrogen receptor}

The estrogen receptor was first found to localize to mitochondria of rabbit uterus and ovary in 2001 [62]. This receptor regulates gene expression by binding to estrogen-response elements (EREs) in gene promoters following the binding of the steroid hormone estrogen to the receptor [63]. Nuclear targets include NRF-1, which, as noted earlier, encodes a transcription factor that stimulates mitochondrial biogenesis and is a 
transcriptional regulator of genes encoding the mitochondrial basal transcription machinery [64] (Figure 2). The indirect regulation of mitochondrial function by the actions of the estrogen receptor has been reviewed elsewhere $[65,66]$.

There is evidence that estrogen acts directly in mitochondria by two pathways: one utilizing the receptor and the other independent of it $[27,67,68]$. The presence of the estrogen receptor in mitochondria is well established; both isoforms, $E R \alpha$ and $E R \beta$, localize to mitochondria in diverse cell lines and tissues, yet their functions remain contentious. EMSAs suggest that ER $\beta$ may bind directly to the D-loop of the mitochondrial genome in MCF-7 breast cancer cells (Figure 1). This binding was stimulated by treatment of the cells with estrogen and inhibited by treatment with ER $\beta$-specific antibodies [69]. It has not, however, been shown that isolated mitochondria respond to estrogen treatment by altering gene expression in an ER $\beta$-dependent fashion.

Other putative functions for the mitochondrial estrogen receptor have focused on protein-protein interactions identified using a bacterial two-hybrid screen. This screen revealed that ER $\alpha$ can interact stably and reproducibly with the mitochondrial protein $17 \beta-$ hydroxysteroid dehydrogenase type 10 , suggesting a role for mitochondrial ER $\alpha$ in regulating cellular steroid metabolism and response [70].

Since cancer is in part a metabolic disease [71], and altered mitochondrial DNA sequence and transcription levels have been observed in both primary tumors and in cancer cell lines [72,73], a mitochondrial role for the estrogen receptor would be relevant to both estrogen receptor biology and the study of hormone-sensitive breast cancer. As with other nuclear factors, however, the indirect action of the estrogen receptor on mitochondrial gene expression is a confounding factor that complicates investigation. Furthermore, as noted above, estrogen seems to regulate mitochondria directly, even in the absence of its receptor [68]. The disagreement over the role of mitochondrial estrogen receptors could be, in part, due to cell-specific functions. Nevertheless, mitochondria are clearly an important target of estrogen hormone action.

\section{Other transcription factors}

Although only a small number of nuclear transcription factors have had a mitochondrial role validated, either in a nucleus-free in organello system or by detection of binding to the mitochondrial genome, there are a number of nuclear transcription factors that have been localized to mitochondria but where the mitochondrial role remains understudied. The glucocorticoid receptor [74], the heterodimeric transcription factor AP-1 [75], and the peroxisome proliferator-activated receptor $\gamma(\operatorname{PPAR} \gamma)$
[76] have all been detected in mammalian mitochondria, and there is some evidence for the glucocorticoid receptor [77] and AP-1 [78] binding to the mitochondrial genome to potentially regulate gene expression.

\section{Future directions}

The five nuclear transcription factors that have been shown to have distinct mitochondrial roles are all involved in signaling pathways: the estrogen receptor and p43 are nuclear hormone receptors activated by a hormone ligand; CREB is phosphorylated in a cyclicAMP-dependent manner; Stat3 is stimulated by growth hormone signaling pathways; and transcription of p53 is activated in response to cell stress. The same signals and signaling pathways regulate the mitochondrial pools of these proteins, so the mitochondrial and the nuclear roles appear to be coordinated regulatory responses. Because these proteins are from different families and the characterized mitochondrial functions are varied, it seems that the development of a mitochondrial role for a nuclear transcription factor is likely to be a common evolutionary strategy for coordinating the two genomes.

The mitochondrial genome and proteome are not only regulated indirectly via processes within the nucleus; they are independently responsive to the needs of the cell. The nuclear transcription factors present in mitochondria are involved in oxidative phosphorylation, cellular metabolism and apoptosis, and their mitochondrion-specific roles are a key part of their biology. The mitochondrial roles of nuclear transcription factors are likely to form a core part of their cellular functions, and yet have been explored in detail in only a handful of cases. The application of new genomics and proteomics techniques may substantially revise our understanding of the regulatory interactions that exist between the nuclear and mitochondrial genomes - with implications for transcription factor biology, mitochondrial regulation and diseases such as cancer, diabetes and obesity.

\section{Author details}

'Cancer Research UK, Cambridge Research Institute, Li Ka Shing Centre, Robinson Way, Cambridge, CB2 ORE, UK. ' University of Cambridge, Department of Oncology, Hutchison/MRC Research Centre, Hills Road, Cambridge, CB2 OXZ, UK. ${ }^{3}$ Centro Nacional de Investigaciones Cardiovasculares, Melchor Fernandez Almagro 3, 28029 Madrid, Spain. ${ }^{4}$ Departamento de Bioquímica, Universidad de Zaragoza, Pedro Cerbuna 9, 50009 Zaragoza, Spain.

Published: 29 July 2010

\section{References}

1. Mootha VK, Bunkenborg J, Olsen JV, Hjerrild M, Wisniewski JR, Stahl E, Bolouri MS, Ray HN, Sihag S, Kamal M, Patterson N, Lander ES, Mann M: Integrated analysis of protein composition, tissue diversity, and gene regulation in mouse mitochondria. Cell 2003, 115:629-640.

2. Pagliarini DJ, Calvo SE, Chang B, Sheth SA, Vafai SB, Ong SE, Walford GA, Sugiana C, Boneh A, Chen WK, Hill DE, Vidal M, Evans JG, Thorburn DR, Carr SA, Mootha VK: A mitochondrial protein compendium elucidates Complex I disease biology. Cell 2008, 134:112-123. 
3. Kurland CG, Andersson SGE: Origin and evolution of the mitochondrial proteome. Microbiol Mol Biol Rev 2000, 64:786-820.

4. Falkenberg M, Larsson NG, Gustafsson CM: DNA replication and transcription in mammalian mitochondria. Annu Rev Biochem 2007, 76:679-699.

5. Acín-Pérez R, Fernández-Silva P, Peleato ML, Pérez-Martos A, Enriquez JA: Respiratory active mitochondrial supercomplexes. Mol Cell 2008, 32:529-539

6. Woodson JD, Chory J: Coordination of gene expression between organellar and nuclear genomes. Nat Rev Genet 2008, 9:383-395.

7. Scarpalla RC: Nuclear control of respiratory gene expression in mammalian cells. J Cell Biochem 2006, 97:673-683.

8. Demonacos C, Tsawdaroglou NC, Djordjevic-Markovic R, Papalopoulou M, Galanopoulos V, Papadogeorgaki S, Sekeris CE: Import of the glucocorticoid receptor into rat liver mitochondria in vivo and in vitro. J Steroid Biochem Mol Biol 1993, 46:401-413.

9. Caelles $C$, Helmberg A, Karin M: p53-dependent apoptosis in the absence of transcriptional activation of p53-target genes. Nature 1994, 370:220-223.

10. Wrutniak C, Cassar-Malek I, Marchal S, Rascle A, Heusser S, Keller J-M, Fléchon J, Dauça M, Samarut J, Ghysdael J, Cabello G: A 43-kDa protein related to c-ErbAa1 is located in the mitochondrial matrix of rat liver. J Biol Chem 1995, 270:16347-16354.

11. Shigenaga MK, Hagen TM, Ames BN: Oxidative damage and mitochondrial decay in aging. Proc Natl Acad Sci USA 1994, 91:10771-10778.

12. Gogvadze V, Orrenius S, Zhivotovsky B: Mitochondria in cancer cells: what is so special about them? Trends Cell Bio/ 2008, 18:165-173.

13. Lowell BB, Shulman Gl: Mitochondrial dysfunction and type 2 diabetes. Science 2005, 307:384-387.

14. Dalgaard LT, Pedersen O: Uncoupling proteins: Functional characteristics and role in the pathogenesis of obesity and Type II diabetes. Diabetologia 2001, 44:946-965.

15. Casas F, Rochard P, Rodier A, Cassar-Malek I, Marchal-Victorion S, Wiesner RJ, Cabello G, Wrutniak C: A variant form of the nuclear triiodothyronine receptor c-ErbAa1 plays a direct role in regulation of mitochondrial RNA synthesis. Mol Cell Biol 1999, 19:7913-7924.

16. Johnson DS, Mortazavi A, Myers RM, Wold B: Genome-wide mapping of in vivo protein-DNA interactions. Science 2007, 316:1497-1502.

17. Pláteník J, Balcar VJ, Yoneda Y, Mioduszewska B, Buchal R, Hynek R, Kilianek L, Kuramoto N, Wilczynski G, Ogita K, Nakamura Y, Kaczmarek L: Apparent presence of Ser133-phosphorylated cyclic AMP response element binding protein ( $p C R E B$ ) in brain mitochondria is due to cross-reactivity of $p C R E B$ antibodies with pyruvate dehydrogenase. J Neurochem 2005, 95:1446-1460.

18. Scharfe C, Zaccaria P, Hoertnagel K, Jaksch M, Klopstock T, Dembowski M, Lill R, Prokisch H, Gerbitz KD, Neupert W, Mewes HW, Meitinger T: MITOP, the mitochondrial proteome database: 2000 update. Nucleic Acids Res 2000 28:155-158.

19. Harper ME, Seifert EL: Thyroid hormone effects on mitochondrial energetics. Thyroid 2008, 18:145-156.

20. Evans RM: The steroid and thyroid hormone receptor superfamily. Science 1988, 240:889-895

21. Weitzel JM, Iwen KAH, Seitz HJ: Regulation of mitochondrial biogenesis by thyroid hormone. Exp Physiol 2003, 88:121-128.

22. Wulf A, Harneit A, Kroger M, Kebenko M, Wetzel MG,Weitzel JM: T3-mediated expression of PGC-1 a via a far upstream located thyroid hormone response element. Mol Cell Endocrinol 2008, 287:90-95.

23. Wrutniak-Cabello C, Casas F, Grandemange S, Seyer P, Busson M, Carazo A, Cabello G: Study of thyroid hormone action on mitochondria opens up a new field of research: mitochondrial endocrinology. Curr Opin Endocrinol Diabetes 2002, 9:387-392.

24. Das B, Heimeier RA, Buchholz DR, Shi YB: Identification of direct thyroid hormone response genes reveals the earliest gene regulation programs during frog metamorphosis. J Biol Chem 2009, 284:34167-34178.

25. Sterling K: Thyroid hormone action: identification of the mitochondrial thyroid hormone receptor as adenine nucleotide translocase. Thyroid 1991 , 1:167-171.

26. Sterling K, Brenner MA: Thyroid hormone action: effect of triiodothyronine on mitochondrial adenine nucleotide translocase in vivo and in vitro. Metabolism 1995, 44:193-199

27. Psarra AMG, Solakidi S, Sekeris CE: The mitochondrion as a primary site of action of steroid and thyroid hormones: Presence and action of steroid and thyroid hormone receptors in mitochondria of animal cells. Mol Cell
Endocrinol 2006, 246:21-33.

28. Enriquez JA, Fernandez-Silva P, Montoya J: Autonomous regulation in mammalian mitochondrial DNA transcription. Biol Chem 1999, 380:737-747.

29. Sato I, Miyado M, Miwa Y, Sunohara M: Expression of nuclear and mitochondrial thyroid hormone receptors in postnatal rat tongue muscle. Cells Tissues Organs 2006, 183:195-205.

30. Enríquez JA, Fernández-Silva P, Garrido-Pérez N, López-Pérez MJ, Pérez-Martos A, Montoya J: Direct regulation of mitochondrial RNA synthesis by thyroid hormone. Mol Cell Biol 1999, 19:657-670.

31. Casas F, Pessemesse L, Grandemange S, Seyer P, Baris O, Gueguen N Ramonatxo C, Perrin F, Fouret G, Lepourry L, Cabello G, Wrutniak-Cabello C: Overexpression of the mitochondrial T3 receptor induces skeletal muscle atrophy during aging. PLOS ONE 2009, 4:e5631.

32. Fernandez-Vizarra E, Enriquez JA, Perez-Martos A, Montoya J, Fernandez-Silva P: Mitochondrial gene expression is regulated at multiple levels and differentially in the heart and liver by thyroid hormones. Curr Genet 2008, 54:13-22.

33. Hai T, Hartman MG: The molecular biology and nomenclature of the activating transcription factor/cAMP response element binding family of transcription factors: activating transcription factor proteins and homeostasis. Gene 2001, 273:1-11.

34. Montminy MR, Bilezikjian LM: Binding of a nuclear protein to the cyclicAMP response element of the somatostatin gene. Nature 1987, 328:175-178.

35. Shaywitz AJ, Greenberg ME: CREB: A stimulus-induced transcription factor activated by a diverse array of extracellular signals. Annu Rev Biochem 1999, 68:821-861.

36. Ryu H, Lee J, Impey S, Ratan RR, Ferrante RJ: Antioxidants modulate mitochondrial PKA and increase CREB binding to D-loop DNA of the mitochondrial genome in neurons. Proc Natl Acad Sci USA 2005, 102:13915-13920.

37. Acin-Perez R, Salazar E, Kamenetsky M, Buck J, Levin LR, Manfredi G: Cyclic AMP produced inside mitochondria regulates oxidative phosphorylation. Cell Metabolism 2009, 9:265-276.

38. Cammarota M, Paratcha G, Bevilaqua LRM, De Stein ML, Lopez M, Pellegrino De Iraldi A, Izquierdo I, Medina JH: Cyclic AMP-responsive element binding protein in brain mitochondria. J Neurochem 1999, 72:2272-2277.

39. De Rasmo D, Signorile A, Roca E, Papa S: CAMP response element-binding protein (CREB) is imported into mitochondria and promotes protein synthesis. FEBS J 2009, 276:4325-4333.

40. Lee J, Kim CH, Simon DK, Aminova LR, Andreyev AY, Kushnareva YE Murphy AN, Lonze BE, Kim KS, Ginty DD, Ferrante RJ, Ryu H, Ratan RR: Mitochondrial cyclic AMP response element-binding protein (CREB) mediates mitochondrial gene expression and neuronal survival. J Biol Chem 2005, 280:40398-40401.

41. Marchenko ND, Zaika A, Moll UM: Death signal-induced localization of p53 protein to mitochondria - a potential role in apoptotic signaling. $J$ Biol Chem 2000, 275:16202-16212.

42. DeLeo $A B$, Jay G, Appella E: Detection of a transformation-related antigen in chemically induced sarcomas and other transformed cells of the mouse. Proc Natl Acad Sci USA 1979, 76:2420-2424.

43. Ginsberg D, Mechta F, Yaniv M, Oren M: Wild-type p53 can down-modulate the activity of various promoters. Proc Natl Acad Sci USA 1991, 88:9979-9983.

44. Erster S, Moll UM: Stress-induced $\mathrm{p} 53$ runs a direct mitochondrial death program: its role in physiologic and pathophysiologic stress responses in vivo. Cell Cycle 2004, 3:1492-1495.

45. Ben-Porath I, Weinberg RA: The signals and pathways activating cellular senescence. Int J Biochem Cell Biol 2005, 37:961-976.

46. Tasdemir E, Maiuri MC, Galluzzi L, Vitale I, Djavaheri-Mergny M, D'Amelio M, Criollo A, Morselli E, Zhu C, Harper F, Nannmark U, Samara C, Pinton P, Vicencio JM, Carnuccio R, Moll UM, Madeo F, Paterlini-Brechot P, Rizzuto R, Szabadkai G, Pierron G, Blomgren K, Tavernarakis N, Codogno P, Cecconi F, Kroemer G: Regulation of autophagy by cytoplasmic p53. Nat Cell Bio/ 2008 , 10:676-687.

47. Kastan MB, Onyekwere O, Sidransky D, Vogelstein B, Craig RW: Participation of p53 protein in the cellular response to DNA damage. Cancer Res 1991, 51:6304-6311.

48. Mihara M, Erster S, Zaika A, Petrenko O, Chittenden T, Pancoska P., Moll UM: p53 has a direct apoptogenic role at the mitochondria. Mol Cell 2003, 11:577-590. 
49. Moll UM, Wolff S, Speidel D, Deppert W: Transcription-independent pro-apoptotic functions of p53. Curr Opin Cell Bio/ 2005, 17:631-636.

50. Yoshida Y, Izumi H, Torigoe T, Ishiguchi H, Itoh H, Kang D, Kohno K: p53 physically interacts with mitochondrial transcription factor $A$ and differentially regulates binding to damaged DNA. Cancer Res 2003, 63:3729-3734.

51. Hanawalt PC: Subpathways of nucleotide excision repair and their regulation. Oncogene 2002, 21:8949-8956.

52. Offer H, Milyavsky M, Erez N, Matas D, Zurer I, Harris CC, Rotter V: Structural and functional involvement of $\mathrm{p} 53$ in BER in vitro and in vivo. Oncogene 2001, 20:581-589.

53. De Souza-Pinto NC, Harris CC, Bohr VA: p53 functions in the incorporation step in DNA base excision repair in mouse liver mitochondria. Oncogene 2004, 23:6559-6568

54. Achanta G, Sasaki R, Feng L, Carew JS, Lu W, Pelicano H, Keating MJ, Huang P: Novel role of $\mathrm{p} 53$ in maintaining mitochondrial genetic stability through interaction with DNA Poly. EMBO J 2005, 24:3482-3492.

55. Bakhanashvili M, Grinberg S, Bonda E, Simon AJ, Moshitch-Moshkovitz S, Rahav G: p53 in mitochondria enhances the accuracy of DNA synthesis. Cell Death Differ 2008, 15:1865-1874

56. Heyne K, Mannebach S, Wuertz E, Knaup KX, Mahyar-Roemer M, Roemer K: Identification of a putative $\mathrm{p} 53$ binding sequence within the human mitochondrial genome. FEBS Lett 2004, 578:198-202.

57. Fearnley IM, Carroll J, Shannon RJ, Runswick MJ, Walker JE, Hirst J: GRIM-19, a cell death regulatory gene product, is a subunit of bovine mitochondrial NADH:ubiquinone oxidoreductase (Complex I). J Biol Chem 2001, 276:38345-38348

58. Lufei C, Ma J, Huang G, Zhang T, Novotny-Diermayr V, Ong CT, Cao X: GRIM-19, a death-regulatory gene product, suppresses Stat3 activity via functional interaction. EMBO J 2003, 22:1325-1335.

59. Zhong Z, Wen Z, Darnell Jr JE: Stat3: A STAT family member activated by tyrosine phosphorylation in response to epidermal growth factor and interleukin-6. Science 1994, 264:95-98.

60. Gough DJ, Corlett A, Schlessinger K, Wegrzyn J, Larner AC, Levy DE: Mitochondrial STAT3 supports Ras-Dependent oncogenic transformation. Science 2009, 324:1713-1716.

61. Wegrzyn J, Potla R, Chwae YJ, Sepuri NB, Zhang Q, Koeck T, Derecka M, Szczepanek K, Szelag M, Gornicka A, Moh A, Moghaddas S, Chen Q, Bobbili S, Cichy J, Dulak J, Baker DP, Wolfman A, Stuehr D, Hassan MO, Fu XY, Avadhani N, Drake Jl, Fawcett P, Lesnefsky EJ, Larner AC: Function of mitochondrial Stat3 in cellular respiration. Science 2009, 323:793-797.

62. Monje $P$, Boland $\mathrm{R}$ : Subcellular distribution of native estrogen receptor a and $\beta$ isoforms in rabbit uterus and ovary. J Cell Biochem 2001, 82:467-479.

63. Carroll JS, Meyer CA, Song J, Li W, Geistlinger TR, Eeckhoute J, Brodsky AS, Keeton EK, Fertuck KC, Hall GF, Wang Q, Bekiranov S, Sementchenko V, Fox EA, Silver PA, Gingeras TR, Liu XS, Brown M: Genome-wide analysis of estrogen receptor binding sites. Nat Genet 2006, 38:1289-1297.

64. Mattingly KA, Ivanova MM, Riggs KA, Wickramasinghe NS, Barch MJ, Klinge CM: Estradiol stimulates transcription of nuclear respiratory factor-1 and increases mitochondrial biogenesis. Mol Endocrinol 2008, 22:609-622.

65. Klinge CM: Estrogenic control of mitochondrial function and biogenesis. J Cell Biochem 2008, 105:1342-1351.

66. Chen JQ, Cammarata PR, Baines CP, Yager JD: Regulation of mitochondrial respiratory chain biogenesis by estrogens/estrogen receptors and physiological, pathological and pharmacological implications. Biochim Biophys Acta 2009, 1793:1540-1570.

67. Bopassa JC, Eghbali M, Toro L, Stefani E: A novel estrogen receptor GPER inhibits mitochondrial permeability transition pore opening and protects the heart against ischemia-reperfusion injury. Am J Physiol Heart Circ Physiol 2010, 298: $\mathrm{H} 16-\mathrm{H} 23$.

68. Moreira PI, Custódio J, Moreno A, Oliveira CR, Santos MS: Tamoxifen and estradiol interact with the flavin mononucleotide site of complex I leading to mitochondrial failure. J Bio/ Chem 2006, 281:10143-10152

69. Chen JQ, Delannoy M, Cooke C, Yager JD: Mitochondrial localization of ERa and ERß in human MCF7 cells. Am J Physiol Endocrinol Metabolism 2004, 286:E1011-E1022.

70. Jazbutyte $V$, Kehl F, Neyses L, Pelzer T: Estrogen receptor alpha interacts with $17 \beta$-hydroxysteroid dehydrogenase type 10 in mitochondria. Biochem Biophys Res Commun 2009, 384:450-454.

71. Wallace DC: A mitochondrial paradigm of metabolic and degenerative diseases, aging, and cancer: a dawn for evolutionary medecine. Annu Rev
Genet 2005, 39:359-407

72. Parrella P, Xiao Y, Fliss M, Sanchez-Cespedes M, Mazarelli P, Rinaldi M, Nicol T, Gabrielson E, Cuomo C, Cohen D, Pandit S, Spencer M, Rabitti C, Fazio VM, Sidransky D: Detection of mitochondrial DNA mutations in primary breast cancer and fine-needle aspirates. Cancer Res 2001, 61:7623.

73. Glaichenhaus N, Leopold P, Cuzin F: Increased levels of mitochondrial gene expression in rat fibroblast cells immortalized or transformed by viral and cellular oncogenes. EMBO J 1986, 5:1261-1265.

74. Koufali MM, Moutsatsou P, Sekeris CE, Breen KC: The dynamic localization of the glucocorticoid receptor in rat C6 glioma cell mitochondria. Mol Cell Endocrinol 2003, 209:51-60.

75. Ogita K, Okuda H, Kitano M, Fujinami Y, Ozaki K, Yoneda Y: Localization of activator protein-1 complex with DNA binding activity in mitochondria of murine brain after in vivo treatment with kainate. J Neurosci 2002, 22:2561-2570

76. Casas F, Domenjoud L, Rochard P, Hatier R, Rodier A, Daury L, Bianchi A Kremarik-Bouillaud P, Becuwe P, Keller J, Schohn H, Wrutniak-Cabello C, Cabello G, Dauça M: A 45 kDa protein related to PPARy2, induced by peroxisome proliferators, is located in the mitochondrial matrix. FEBS Lett 2000, 478:4-8.

77. Demonacos C, Djordjevic-Markovic R, Tsawdaroglou N, Sekeris CE: The mitochondrion as a primary site of action of glucocorticoids: the interaction of the glucocorticoid receptor with mitochondrial DNA sequences showing partial similarity to the nuclear glucocorticoid responsive elements. J Steroid Biochem Mol Biol 1995, 55:43-55.

78. Ogita K, Fujinami Y, Kitano M, Yoneda Y: Transcription factor activator protein-1 expressed by kainate treatment can bind to the non-coding region of mitochondrial genome in murine hippocampus. J Neurosci Res 2003, 73:794-802

79. Maughan R: Carbohydrate metabolism. Surgery 2009, 27:6-10.

80. Boyer PD: A model for conformational coupling of membrane potential and proton translocation to ATP synthesis and to active transport. FEBS Lett 1975, 58:1-6.

81. Vesteg M, Krajčovič J: Origin of eukaryotic cells as a symbiosis of parasitic alpha-proteobacterium in the periplasm of two-membrane-bounded sexual pre-karyotes. Commun Integr Biol 2008, 1:104-113.

82. Bibb MJ, Van Etten RA, Wright CT, Walberg MN, Clayton DA: Sequence and gene organization of mouse mitochondrial DNA. Cell 1981, 26:167-180.

83. Andersson SG, Zomorodipour A, Andersson JO, Sicheritz-Pontén T, Alsmark UC, Podowski RM, Näslund AK, Eriksson AS, Winkler HH, Kurland CG: The genome sequence of Rickettsia prowazekii and the origin of mitochondria. Nature 1998, 396:133-140.

84. Masters BS, Stol LL, Clayton DA: Yeast mitochondrial RNA polymerase is homologous to those encoded by bacteriophages T3 and T7. Cell 1987, 51:89-99.

85. Kelly DP, Scarpulla RC: Transcriptional regulatory circuits controlling mitochondrial biogenesis and function. Genes Dev 2004, 18:357-368

86. Anderson S, Bankier AT, Barrell BG: Sequence and organization of the human mitochondrial genome. Nature 1981, 290:457-465

87. Montoya J, Christianson T, Levens D: Identification of initiation sites for heavy-strand and light-strand transcription in human mitochondrial DNA. Proc Natl Acad Sci USA 1982, 79:7195-7199.

88. Cotney J, MCKay SE, Shadel GS: Elucidation of separate, but collaborative functions of the rRNA methyltransferase-related human mitochondrial transcription factors $B 1$ and $B 2$ in mitochondrial biogenesis reveals new insight into maternally inherited deafness. Hum Mol Genet 2009, 18:2670-2682

89. Ojala D, Montoya J, Attardi G: tRNA punctuation model of RNA processing in human mitochondria. Nature 1981, 290:470-474

90. Milanesi L, Vasconsuelo A, de Boland AR, Boland R: Expression and subcellular distribution of native estrogen receptor $\beta$ in murine $\mathrm{C} 2 \mathrm{C} 12$ cells and skeletal muscle tissue. Steroids 2009, 74:489-497.

91. Casas F, Pessemesse L, Grandemange S, Seyer P, Gueguen N, Baris O, Lepourry L, Cabello G, Wrutniak-Cabello C: Overexpression of the mitochondrial T3 receptor p43 induces a shift in skeletal muscle fiber types. PLOS ONE 2008, 3:e2501

doi:10.1186/gb-2010-11-7-215

Cite this article as: Leigh-Brown S, et al: Nuclear transcription factors in

mammalian mitochondria. Genome Biology 2010, 11:215. 